\title{
Photo-Induced Conductivity of Heterojunction GaAs/Rare-Earth Doped $\mathrm{SnO}_{2}$
}

\author{
Cristina de Freitas Bueno ${ }^{\mathrm{a}}$, Diego Henrique de Oliveira Machado, \\ Tatiane de Fátima Pineiz $z^{\mathrm{a}}$, Luis Vicente de Andrade Scalvi ${ }^{\mathrm{a}, \mathrm{b} *}$
}

\author{
aPhysics Department, School of Sciences, São Paulo State University - UNESP, Bauru, SP, Brazil \\ ${ }^{\mathrm{b}}$ Meteorological Research Institute, São Paulo State University - UNESP, Bauru, SP, Brazil
}

Received: April 7, 2012; Revised: March 1, 2013

\begin{abstract}
Rare-earth doped $\left(\mathrm{Eu}^{3+}\right.$ or $\left.\mathrm{Ce}^{3+}\right)$ thin layers of tin dioxide $\left(\mathrm{SnO}_{2}\right)$ are deposited by the sol-gel-dipcoating technique, along with gallium arsenide ( $\mathrm{GaAs}$ ) films, deposited by the resistive evaporation technique. The as-built heterojunction has potential application in optoelectronic devices, because it may combine the emission from the rare-earth-doped transparent oxide, with a high mobility semiconductor. Trivalent rare-earth-doped $\mathrm{SnO}_{2}$ presents very efficient emission in a wide wavelength range, including red (in the case of $\left.\mathrm{Eu}^{3+}\right)$ or blue $\left(\mathrm{Ce}^{3+}\right)$. The advantage of this structure is the possibility of separation of the rare-earth emission centers, from the electron scattering, leading to an indicated combination for electroluminescence. Electrical characterization of the heterojunction $\mathrm{SnO}_{2}: \mathrm{Eu} / \mathrm{GaAs}$ shows a significant conductivity increase when compared to the conductivity of the individual films. Monochromatic light excitation shows up the role of the most external layer, which may act as a shield (top GaAs), or an ultraviolet light absorber sink (top RE-doped $\mathrm{SnO}_{2}$ ). The observed improvement on the electrical transport properties is probably related to the formation of short conduction channels in the semiconductors junction with two-dimensional electron gas (2DEG) behavior, which are evaluated by excitation with distinct monochromatic light sources, where the samples are deposited by varying the order of layer deposition.
\end{abstract}

Keywords: tin dioxide, gallium arsenide, heterojunction, interface, electrical conductivity

\section{Introduction}

Seeking for innovative technologies combining semiconductor materials, the conjunction of the rare-earth (RE) doped transparent oxide semiconductor $\mathrm{SnO}_{2}$ with a high mobility semiconductor, GaAs, leads to a combination with physically desirable properties. Then, the deposition of GaAs layer and $\mathrm{SnO}_{2}$ layer in the form of thin films was accomplished, generating simple heterostructures $\mathrm{SnO}_{2}: \mathrm{RE} / \mathrm{GaAs}$ or vice-versa. The advantage of this structure is the possibility of separation of the rare-earth emission centers, incorporated in the tin dioxide layer, from the electron scattering in the GaAs layer, leading to an indicated combination for electroluminescence. Tin dioxide $\left(\mathrm{SnO}_{2}\right)$ is a wide bandgap semiconductor (3.6-4.0 $\left.\mathrm{eV}^{[1]}\right)$, with useful electrical and optical properties for several types of devices, such as transparent electrodes and gas sensors ${ }^{2}$. Trivalent rare-earth ions used as doping in this paper are $\mathrm{Eu}^{3+}$ with efficient emission in the red range, and $\mathrm{Ce}^{3+}$, with radiative transition leading to blue emission. On the other hand, gallium arsenide (GaAs) is one of the most essential semiconductors for microelectronics, used in applications where the interaction of light and electricity is required ${ }^{3}$, mainly due to the direct bandgap transition, leading the excited electrons to occupy preferentially the $\Gamma$ valley of the conduction band, of higher mobility ${ }^{4}$.

*e-mail: scalvi@fc.unesp.br
The trivalent rare-earth incorporation in semiconductor has grown significantly in the last years, leading to widely investigated processes, because RE present optical transitions in and wide range, from ultraviolet to infrared, giving birth to technologically interesting emissions, including electroluminescent devices ${ }^{5}$. The Eu-doped matrix $\mathrm{SnO}_{2}$ presents two types of $\mathrm{Eu}^{3+}$ incorporation: at symmetry sites, substitutional to $\mathrm{Sn}^{4+}$, or at asymmetric sites, at particles surface, due to doping segregation ${ }^{6}$. In both cases the luminescent properties characteristics are in the range $570-720 \mathrm{~nm}^{[7]}$. In the case of the ion $\mathrm{Ce}^{3+}$, it presents $4 \mathrm{f}^{1}$ electronic configuration at the ground state and $5 \mathrm{~d}^{1}$ at excited state. Optical transitions between these states are allowed electric dipole transitions. Level $5 \mathrm{~d}$ presents strong lattice interaction and the first dipole transition suffers a spectroscopic redshift when incorporated into a crystal, being shifted towards lower energy compared to the free ion $^{8}$. Broad blue emission has been recorded around $489 \mathrm{~nm}$ in a host matrix of zinc borosilicate glass 9 .

Low quantum efficiency in the luminescence process

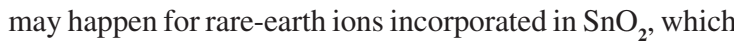
is generally attributed to the difference between radius and charge of doping ions and $\mathrm{Sn}^{4+[10]}$. In order to avoid this problem, the materials production using nanoparticles as building blocks is recommended ${ }^{10}$, and the sol-gel process is appropriate ${ }^{11,12}$ for this purpose. Low solubility limit of about 0.05 at $\%$ has been observed for $\mathrm{Eu}^{3+}$ doping, and the 
excess of doping segregates at grain boundary layer ${ }^{13}$. This low solubility is probably due to the difference between ionic radius, since for $\mathrm{Sn}^{4+}$ it is $0.69 \AA$ whereas for $\mathrm{Eu}^{3+}$ it is $0.95 \AA$. For $\mathrm{Ce}^{3+}$ the solubility must be even lower, since the ion is larger, $1.01 \AA^{[14]}$.

Heterojunctions using transparent oxides deposited on top of semiconductors have been presented recently. High-quality self-textured $\mathrm{ZnO}$ films has been grown on top of a GaAs substrate, forming a heterojunction with characteristic of rectifying diode, with blue-violet and infrared electroluminescence ${ }^{15}$, suitable for optical fiber telecommunications applications. Promising devices for the development of solid-state lighting were achieved by $n-\mathrm{ZnO} / n-\mathrm{GaAs}$ heterostructured light-emitting diodes ${ }^{16}$. Other combinations of semiconductor heterojunctions with $\mathrm{SnO}_{2}$ have been successfully used such as with gallium selenide $(\mathrm{GaSe})^{17}$. The combination of $\mathrm{SnO}_{2}$ with $\mathrm{Al}_{2} \mathrm{O}_{3}$ layer deposited by similar processes of the films deposition used in this paper, has led to a simple device with a potential combination for application as transparent transistors ${ }^{18}$.

The deposition of heterojunctions with smooth and atomic quality surfaces has become a possibility since the late 60s, when the growth of epitaxy layers became available. This sort of deposition may lead to the formation of a quantum well at the interface, due to the interrupting atomic band diagrams of distinct materials. This quantum well may present energy levels below the conduction band bottom of one or both materials and, may give birth to a two-dimensional electron gas (2DEG). The interface of semiconductor heterojunctions carries intrinsic states, and the Fermi level at the surface is different from the bulk, giving origin to a band bending ${ }^{19}$. This band bending may lead to a charge accumulation layer at the interface and to the dynamics of excited electrons as a two-dimensional electron gas. The quantization of charge near surface and interface layers was first demonstrated by Tsui ${ }^{20}$, using subband energies measurements. A triangular quantum well forms at the semiconductors interface, usually referred to as the heterointerface. Normally, only the quantum mechanical ground state in the triangular well is populated, but the excited levels can be filled with the application of an electric field. It is also possible to grow a semiconductor layers structure, resulting in a square well, where a lower bandgap semiconductor is sandwiched between two layers of a higher bandgap semiconductor. The dopants are removed from the lower conduction band semiconductor, which is referred to as modulation doping, a technique first demonstrated by Dingle and coworkers in $1978^{21}$ for the system GaAs/AlGaAs. This structure spatially separates conduction electrons and their parent donor impurity atoms, thereby reducing the influence of ionized and neutral impurity scattering on the electron motion.

A 2DEG has recently been found also at the interface between two insulating oxides $\mathrm{LaAlO}_{3}$ and $\mathrm{SrTiO}_{3}{ }^{[22]}$, attracting significant interest due to possible applications in all-oxide electronic devices, and has stimulated intense research activity in this field. A tunable conductivity of the $\mathrm{LaAlO}_{3} / \mathrm{SrTiO}_{3}$ interfaces leads to significant attention to the proposal of oxide electronic structures where electronic confinement can be reduced to the nanometer range. The mechanisms for the conductivity modulation is a result of electrical modification of the $\mathrm{LaAlO}_{3}$ surface, leading to a change in the 2DEG density at the $\mathrm{LaAlO}_{3} /$ $\mathrm{SrTiO}_{3}$ interface. Wang et al. ${ }^{23}$ employed first-principles calculations to investigate the system $\mathrm{KNbO}_{3} / A \mathrm{TiO}_{3}(001)$ ( $A=\mathrm{Sr}, \mathrm{Pb}$, and $\mathrm{Ba}$ ) heterostructures where perovskites ferroelectrics, $\mathrm{KNbO}_{3}, \mathrm{PbTiO}_{3}$, and $\mathrm{BaTiO}_{3}$, are used as oxide constituents to create a $2 \mathrm{DEG}$ at the interface. The two-dimensional electron gas has unique properties that are promising for applications in all-oxide electronic devices, since it is possible to control the 2 DEG properties by external stimulus. Their results suggest that the polar $\left(\mathrm{NbO}_{2}\right)^{+} /(A \mathrm{O})^{\circ}$ interface in these heterostructures favors the formation of $2 \mathrm{DEG}$ similar to that at the $(\mathrm{LaO})^{+} /\left(\mathrm{TiO}_{2}\right)^{\circ}$ interface in a $\mathrm{LaAlO}_{3} / \mathrm{SrTiO}_{3}$ heterostructure. The formation of $2 \mathrm{DEGs}$ at complex oxide interfaces is directly influenced by the oxide electronic properties. The local electron correlations may control the 2DEG by inserting a single atomic layer of a rare-earth oxide ( $\mathrm{RO})$ [( $\mathrm{R}$ is lanthanum $(\mathrm{La})$, praseodymium (Pr), neodymium (Nd), samarium (Sm), or yttrium (Y)] into an epitaxial strontium titanate oxide $\left(\mathrm{SrTiO}_{3}\right)$ matrix ${ }^{24}$. These structures result in conducting 2DEGs at the inserted layer, and the interfacial conductivity is dependent on electronic correlations that decay spatially into the $\mathrm{SrTiO} 3$ matrix.

Considering that the formation of a $2 \mathrm{DEG}$ is a possibility at the interface $\mathrm{SnO}_{2} / \mathrm{GaAs}^{25}$, the proposal of this work is to combine the doping of some trivalent rare-earths ions in $\mathrm{SnO}_{2}$ with a GaAs layer, giving birth to a simple heterojunction $\mathrm{SnO}_{2}: \mathrm{RE}^{3+} / \mathrm{GaAs}$. The electrical characteristic of the interface between both semiconductors indicates a very promising performance related to the electrical transport. The evaluation of conductivity as function of temperature data points to a conductivity increase when compared to individual films. In order to understand the rule on the electrical transport, samples are grown in opposite order and the temperature-dependent conductivity under monochromatic light excitation with distinct light sources is measured.

\section{Experimental}

The $\mathrm{SnO}_{2}$ colloidal suspension was prepared by the sol-gel process from an aqueous solution, using appropriate precursor reagents, as described elsewhere ${ }^{6,26} \cdot \mathrm{SnO}_{2}: \mathrm{Eu}^{3+}$ and $\mathrm{SnO}_{2}: \mathrm{Ce}^{3+}$ thin films were deposited via dip-coating on borosilicate glass or on top of a GaAs layer, at a dipping rate of $10 \mathrm{~cm} / \mathrm{min}$. Between each layer (total $=10$ ), the film was fired for 10 minutes at $400{ }^{\circ} \mathrm{C}$, and a final thermal annealing at $550{ }^{\circ} \mathrm{C}$ by 1 hour, was also carried out. GaAs was deposited by the resistive evaporation technique on soda-lime glass or on top of a $\mathrm{SnO}_{2}$ layer, using $\mathrm{W}$ crucible, in a Edwards AUTO 500 evaporation system, with pressure of about $10^{-6}$ mbar. Indium (In) metallic electrodes were deposited by the same technique, using Mo crucible, trough a shadow mask. The electrodes annealing was done at $150{ }^{\circ} \mathrm{C}$ for 30 minutes.

X-ray diffraction data of films were obtained with a RIGAKU diffractometer, model D/MAX-2100/PC, with $\mathrm{CuK} \alpha(\lambda=1.5406 \AA)$ radiation and scanning rate of $1 \% \mathrm{~min}$ in the range of $20-80^{\circ}(2 \theta)$, at room temperature. A current of $20 \mathrm{~mA}$ and a potential of $40 \mathrm{kV}$ were used. 
The electrical characterization was done in a He closed cycle cryostat from Cryogenics, coupled to a Lake Shore Cryotronics temperature controller, in the range 25-300 K. The electrical signal data collecting was done through a Keithley electrometer, model 617. Distinct light source were used to verify the possibility of charge carrier excitation in the samples geometries: 1) the fourth harmonic of Nd:YAG pulsed laser $(266 \mathrm{~nm}-10 \mathrm{~Hz})$, with $0.5 \mathrm{MW}$ peak power and $30 \mathrm{~mW}$ average power, 2) a He-Ne laser (628 nm), with $5 \mathrm{~mW}$ of power, 3 ) a blue InGaN light emitting diode (LED) with average wavelength of $450 \mathrm{~nm}$ and average power of $15 \mathrm{~mW}$. The procedure was the same in all the cases, with the excitation carried out for 5 or 6 minutes at fixed temperature, before the data collecting and/or warming up of sample temperature.

\section{Results and Discussion}

SEM of cross section and surface of $\mathrm{SnO}_{2}: 2.0$ at $\% \mathrm{Eu} / \mathrm{GaAs}$ sample has been published elsewhere ${ }^{27}$. The interface film/substrate as well as the interface $\mathrm{SnO}_{2} / \mathrm{GaAs}$ present good adherence. However these interfaces probably contain a high density of atomic and structural defects due to the deposition methods. The metallic junction of these two materials gives rise to a discontinuity in the conduction and valence band profiles. The carriers migrate from a material to the other until the thermodynamic equilibrium is reached (Fermi level equality of both sides), resulting in the band bending close to the interface. Consequently, a two dimensional electron gas (2DEG) is allowed to be formed at the interface $\mathrm{SnO}_{2} / \mathrm{GaAs}$, where electrons are confined in quantized states leading the low resistivity transport parallel to the sample conductive channel ${ }^{25}$. The estimated thickness for $\mathrm{SnO}_{2}: 2.0$ at $\% \mathrm{Eu} / \mathrm{GaAs}$ evaluated from SEM image is about $350 \mathrm{~nm}$ for $\mathrm{SnO}_{2}: 2 \% \mathrm{Eu}$ film and $400 \mathrm{~nm}$ for the GaAs thin film. The top GaAs layer has a rather inhomogeneous surface as expected from the resistive evaporation technique. However, the distribution of particles throughout the surface is rather uniform with an average size of about $90 \mathrm{~nm}$. The formation of the two-dimensional electron gas is expected in single crystals samples, grown by MBE for instance, but in our case, the deposition methods themselves should lead to an uneven surface, with a high density of interfacial defects. However, the quality of the interface in $\mathrm{SnO}_{2}: 2.0$ at $\% \mathrm{Eu} / \mathrm{GaAs}$ is evident ${ }^{27}$. The same sort of images for $\mathrm{SnO}_{2}: 0.5$ at $\% \mathrm{Eu} / \mathrm{GaAs}$ sample leads to similar results, with an estimated thickness of about $350 \mathrm{~nm}$ and $250 \mathrm{~nm}$, for the film of $\mathrm{SnO}_{2}: 0.5$ at $\% \mathrm{Eu}$ and $\mathrm{GaAs}$, respectively, followed by a disorganized layer, due to the used GaAs mass for evaporation, which was three times higher in this case. The disorganized particles layer at sample surface of $\mathrm{SnO}_{2}: 0.5$ at $\% \mathrm{Eu} / \mathrm{GaAs}$ heterojunction, suggests a limiting thickness for the top film, above that the particles grow disordered, with weaker adherence to the film. That is probably related to the excess of Arsenium (As), since X-ray dispersive energy results reveal a higher percentage of As compared to $\mathrm{Ga}$, in GaAs deposited by resistive evaporation ${ }^{28}$.

Figure 1a shows electrical conductivity data as function of temperature, measured in the dark, for samples of $\mathrm{SnO}_{2}: 2.0$ at $\% \mathrm{Eu}$ (about $350 \mathrm{~nm}$ thick), GaAs (about $325 \mathrm{~nm}$ thick) and of the heterojunction $\mathrm{SnO}_{2}: 2 \% \mathrm{Eu} / \mathrm{GaAs}$ with individual layers with quite similar thicknesses, as already discussed. Figure 1b shows the X-ray difractograms for heterojunctions $\mathrm{SnO}_{2}: 2 \% \mathrm{Eu} / \mathrm{GaAs}$ and $\mathrm{SnO}_{2}: 0.5 \% \mathrm{Eu} /$ GaAs. It is seen in Figure 1a that electrical conductivity of the heterojunction $\mathrm{SnO}_{2}: 2 \% \mathrm{Eu} / \mathrm{GaAs}$ is higher than the conductivity of the films deposited individually. Although the formation of a two dimensional electron gas (2DEG) is expected in heterojunctions built from single crystals, in the case of the heterojunction $\mathrm{SnO}_{2}: 2 \% \mathrm{Eu} / \mathrm{GaAs}$ obtained in this work, the higher conductivity allows thinking of the possible formation of small 2DEG channels, giving better mobility to the conducting electrons, explaining the higher conductivity of the heterojunction compared to the individuals films. Published SEM of the cross section ${ }^{27}$, shows that the interface substrate $/ \mathrm{SnO}_{2}$ as well as the

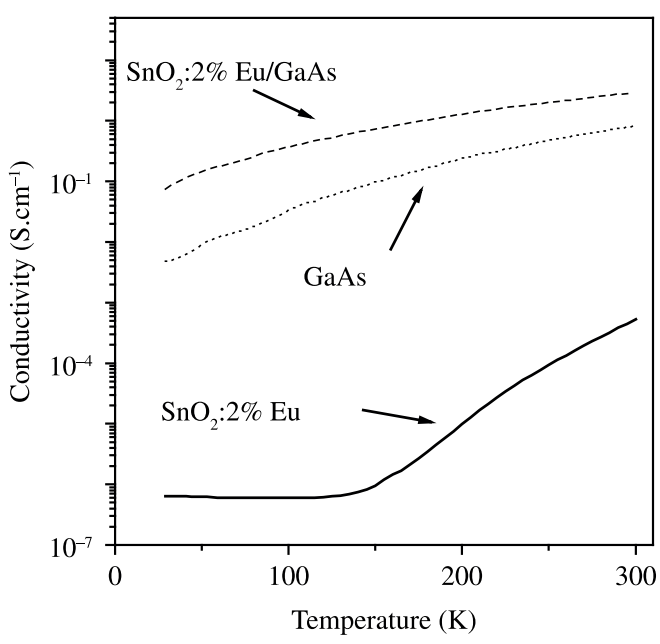

(a)

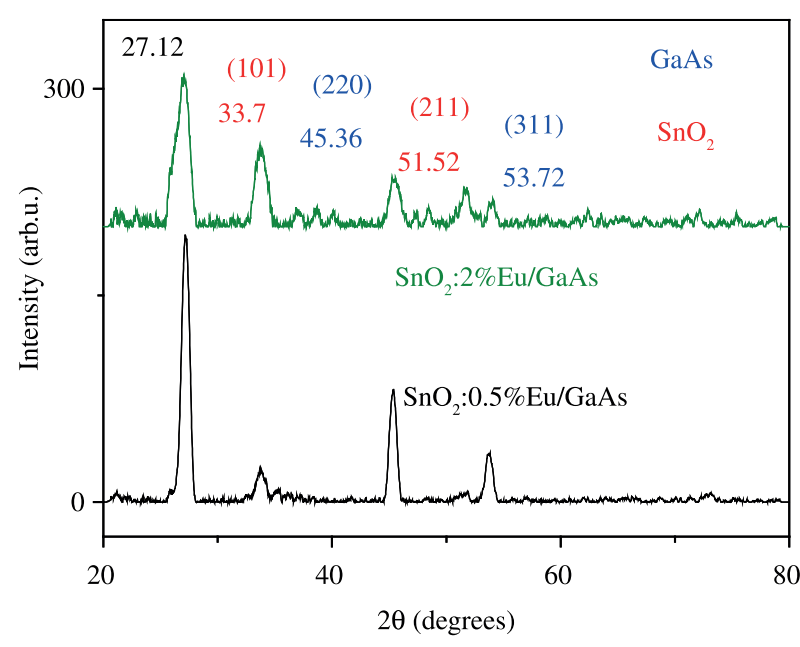

(b)

Figure 1. a) Electrical conductivity of $\mathrm{GaAs}, \mathrm{SnO}_{2}$ thin films and heterojunction $\mathrm{SnO}_{2}: 2 \% \mathrm{Eu} / \mathrm{GaAs}$, as function of temperature. b) $\mathrm{X}$-ray diffractogram of heterojunctions $\mathrm{SnO}_{2}: 2 \% \mathrm{Eu} / \mathrm{GaAs}$ and $\mathrm{SnO}_{2}: 0.5 \% \mathrm{Eu} / \mathrm{GaAs}$. 
interface $\mathrm{SnO}_{2} / \mathrm{GaAs}$ present good adherence, with no indication of interdiffusion from one material to the other. Diffractograms shown in Figure 1b present the noisy and diffuse profile typical of nano-crystallized domain, where the building blocks are nanocrystallites. The labeled peaks correspond to the planes of rutile structure of tin dioxide (JCPDS- 41-1445) and planes of GaAs (JCPDS-80-0016) ${ }^{29}$. Characteristic peaks of $\mathrm{SnO}_{2}$ are seen at $33.7^{\circ}$ and $51.5^{\circ}$ corresponding to crystallographic planes (101) and (211), and characteristic peaks of GaAs at $45.4^{\circ}$ and $53.7^{\circ}$, related to planes (220) and (311). At $27.1^{\circ}$ there is probably a overlapping of two peaks: one related to plane (100), characteristic of $\mathrm{SnO}_{2}$, and another peak corresponding to plane (111) of GaAs. The GaAs peaks are more evident (intense) at the $\mathrm{SnO}_{2}: 0.5 \mathrm{at} \% \mathrm{Er} / \mathrm{GaAs}$ diffractogram, due to the higher amount of evaporated material and the disordered surface layer, masking the $\mathrm{SnO}_{2}$ film characterization, since the transparent oxide is the deeper layer. The average crystallite sizes are estimated by the Scherrer equation for GaAs films deposited by resistive evaporation are $11 \mathrm{~nm}$, $7.5 \mathrm{~nm}$ and $10 \mathrm{~nm}$ for the crystallographic planes (111), (220) and (311), respectively. Comparing these values with the particles size estimated from the SEM images ${ }^{27}$, we may state that the larger particles are grains constituted by smaller crystallite units.

Figure 2 shows optical absorption data of $\mathrm{GaAs}, \mathrm{SnO}_{2}$ and $\mathrm{SnO}_{2}: 2 \% \mathrm{Eu} / \mathrm{GaAs}$ thin films, and the inset in Figure 2 brings optical absorption of small crystals deposited by water evaporation from the solution of $\mathrm{SnO}_{2}: 4 \mathrm{at} \% \mathrm{Eu}$. The transition ${ }^{7} \mathrm{~F}_{0} \rightarrow{ }^{5} \mathrm{D}_{3}$ is more clearly evidenced in short range. The results of Figure 2 show clearly that for the thicker GaAs layer the absorption becomes stronger and, besides, the optical absorption of the $\mathrm{SnO}_{2}: 2 \% \mathrm{Eu} / \mathrm{GaAs}$ heterojunction is an evident contribution from both layers, even though the GaAs contribution must be stronger because it has lower bandgap energy, and shall absorb the incident light before. The observed $\mathrm{Eu}^{3+}$ electronic transition evidenced in the inset of Figure 2 shows that the rare-earth doping is clearly incorporated into the $\mathrm{SnO}_{2}$ matrix. Besides, it provides an

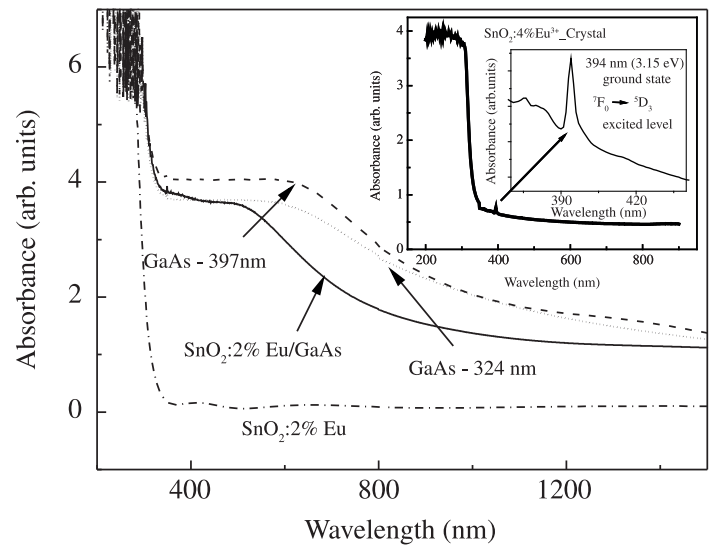

Figure 2. Optical absorption of $\mathrm{GaAs}, \mathrm{SnO}_{2}$ and $\mathrm{SnO}_{2}: 2 \% \mathrm{Eu} / \mathrm{GaAs}$ thin films. Inset: optical absorption of crystals deposited by water evaporation from the solution of $\mathrm{SnO}_{2}: 4$ at $\% \mathrm{Eu}$, where the transition ${ }^{7} \mathrm{~F}_{\mathrm{o}} \rightarrow{ }^{5} \mathrm{D}_{3}$ is more clearly evidenced in short range. interesting wavelength to optically excite these samples. $\mathrm{Eu}^{+3}$ centers have been excited in the $\mathrm{SnO}_{2}$ matrix directly or indirectly ${ }^{6}$. In the first case, excitation with $\mathrm{Ar}^{+}$laser line $488 \mathrm{~nm}(2.53 \mathrm{eV})$ provides a resonant source with the transition ${ }^{7} \mathrm{~F}_{2} \rightarrow{ }^{5} \mathrm{D}_{2}$ of $\mathrm{Eu}^{3+}$. Excitation with above $\mathrm{SnO}_{2}$ bandgap, for instance with the fourth harmonic of a $\mathrm{Nd}$ :YAG laser $(266 \mathrm{~nm})^{6,30}$ supplies photons with energy $(4.65 \mathrm{eV})$ to provide band-to-band excitation, followed by energy transfer to $\mathrm{Eu}^{3+}$ excited level. After excitation to level ${ }^{5} \mathrm{D}_{2}$, electrons decay non-radiatively to ${ }^{5} \mathrm{D}_{0}$ level and then emit photons according to transition ${ }^{5} \mathrm{D}_{0} \rightarrow{ }^{7} \mathrm{~F}_{1}$ and ${ }^{5} \mathrm{D}_{0} \rightarrow{ }^{7} \mathrm{~F}_{2}$. The first one is a magnetic dipole transition and its intensity is not affected by structural changes of the nearest neighborhood, whereas the transition ${ }^{5} \mathrm{D}_{0} \rightarrow{ }^{7} \mathrm{~F}_{2}$ is ruled by electric dipoles, being hypersensitive to the local crystalline field. More doped samples exhibits particularly the second transition in the luminescence spectra, since the doping ions are located preferentially at grain boundary, far from the symmetry centers. In the case of the samples investigated in this work, the optical characterization yields the preferential location of doping ions at grain boundary layer, due to the high doping concentration (2 to 4 at $\%$ ). The reported transition of the inset of Figure 2 has not been exploited yet for optical excitation.

Figure 3 represents the monochromatic light excitation with the three light sources as described in the Experimental section. In order to evaluate the role of these light excitation on the sample conductivity, and to characterize the electrical transport through the sample, conductivity as a function of temperature was plotted after monochromatic light excitation of the $\mathrm{SnO}_{2}: 2$ at $\% \mathrm{Eu} / \mathrm{GaAs}$ sample with three different light sources. This experiment concerns the verification of parallel participation of the individual layers or the 2DEGs in the electrical transport in the sample, perpendicular to sample deposition direction. The sample was irradiated for 5 min at low temperature $(35 \mathrm{~K})$, followed by an increase of temperature in the dark at a rate of $3 \mathrm{~K} / \mathrm{min}$, where the sample conductivity is evaluated. The inset in Figure 3 shows the relative variation of resistitivity compared with

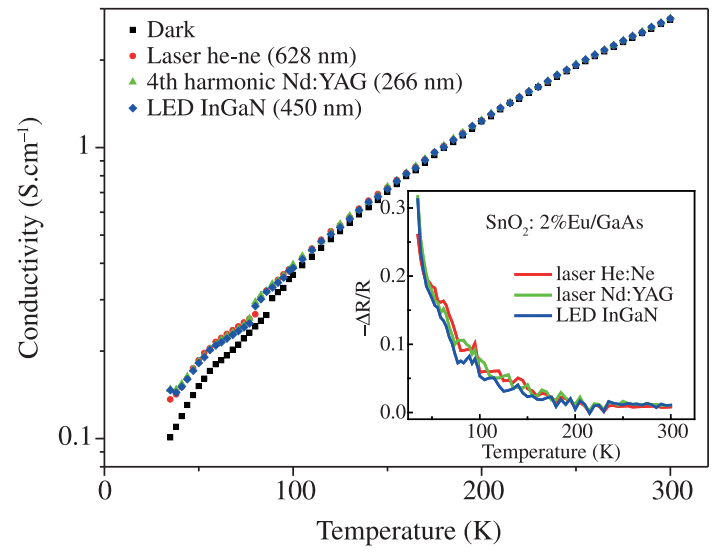

Figure 3. Conductivity as function of temperature for the heterojunction $\mathrm{SnO}_{2}: 2 \% \mathrm{Eu} / \mathrm{GaAs}$ in the dark and under illumination with distinct light sources. Inset: resistivity variation $(-\Delta R / R)$ evaluated form the photoinduced resistiviy data. 
the resistivity in the dark. As can be seen in Figure 3 and confirmed in the inset, the variation in resistivity (and then, the conductivity) is rather low and takes place mainly at low temperature range, below $100 \mathrm{~K}$. All the light sources have similar effects on the sample conductivity. The highest variation is exactly at the lowest temperature, just after the illumination is removed, as expected, but no permanent variation is recorded, since in all cases the conductivity returns to its dark value, when the temperature is increased.

Although the energies of the light sources are rather different, the relative current excitation is comparable, independent of excitation energies. It is important to mention that $628 \mathrm{~nm}$ is a higher wavelength (lower energy) compared with the $\mathrm{SnO}_{2}$ bandgap (about $350 \mathrm{~nm}$ ), as is $450 \mathrm{~nm}$, which is far below the GaAs bandgap (about $870 \mathrm{~nm}$ ) but still above the $\mathrm{SnO}_{2}$ bandgap. The wavelength of $266 \mathrm{~nm}$ is below the $\mathrm{SnO}_{2}$ bandgap (higher energy) and then, the corresponding energy (4.65 eV) was previously efficiently used for $\mathrm{SnO}_{2}$ matrix excitation, concerning electron-hole generation in the evaluation of photo-induced electrical properties ${ }^{30}$, as well as in the energy transfer process for $\mathrm{Eu}^{3+}$ excitation, leading to a highly efficient luminescence, in the evaluation of Eu-doped $\mathrm{SnO}_{2}$ emission properties ${ }^{6}$.

The excitation processes can be outlined by considering that the GaAs film is grown on top of the $\mathrm{SnO}_{2}$ film. The radiation emitted by the source reaches the GaAs layer directly, which acts as a shield for the $\mathrm{SnO}_{2}$ layer. The GaAs film is thick enough to avoid light reaching the $\mathrm{SnO}_{2}$ layer. The results presented in Figure 3, the similar excitation of the three light sources, ensures that they are not exciting $\mathrm{SnO}_{2}$ intrabandgap trapped electrons or electron-hole pairs in $\mathrm{SnO}_{2}$. Otherwise, a rather higher conductivity increase would be provided by the population of excited states in the $2 \mathrm{DEG}$. At this point one must recall that excitation with the fourth harmonic of the Nd:YAG laser $(266 \mathrm{~nm})$ is related to the matrix band-to-band excitation, followed by energy transfer to $\mathrm{Eu}^{3+}$ ions ${ }^{6}$, leading to emissions: ${ }^{5} \mathrm{D}_{0}$ $\rightarrow{ }^{7} \mathrm{~F}_{2}(2.02 \mathrm{eV})$ and ${ }^{5} \mathrm{D}_{0} \rightarrow{ }^{7} \mathrm{~F}_{1}(2.10 \mathrm{eV})$ for ions located close to the particles' surfaces, or at $\mathrm{Sn}^{4+}$ substitutional sites, respectively. Concerning the electrical properties, Eu-doped thin films were appropriately excited with the same $266 \mathrm{~nm}$ laser line, and the decay of excited conductivity was analyzed $^{30}$. This excitation leads to strong excitation of the matrix; moreover, it should depend on the $\mathrm{Eu}^{3+}$ concentration in the matrix, similar to the photoluminescence data, because the Eu doping concentration in these heterojunctions reported herein is quite similar to the luminescent xerogels ${ }^{6}$, with distinct PL spectra when excited with the same light source. In the results shown in Figure 3, the observed excitation is only related to the GaAs band-to-band, because all the light sources used have energy above the GaAs bandgap (1.42 eV) and the use of a source with energy higher than the $\mathrm{SnO}_{2}$ bandgap ( $266 \mathrm{~nm}, 4.65 \mathrm{eV}$ ) does not cause any meaningful modification in the photo-induced current. Thus, there are two possible explanations for the conductivity increase observed in Figure 3: 1) electrons are being excited from the GaAs to the 2DEG. With increasing temperature, these electrons occupy higher levels in the potential well, until they have enough energy to become delocalized at the GaAs conduction band, and recombine with the holes in the GaAs side ${ }^{27}$. Another possibility is that the capture of photoexcited electrons could evolve into some sort of lattice relaxation, with electron trapping becoming a thermally activated process, where the electrons will overcome the capture barrier ${ }^{31}$. This could explain why the electron-hole recombination does not happen instantaneously, as shown in Figure 3.

In order to confirm the behavior of the GaAs layer, as a shield in the photo-induced electrical transport mechanisms of this sort of heterojunction, we have inverted the deposition order, and a heterojunction $\mathrm{GaAs} / \mathrm{SnO}_{2}: 2 \mathrm{at} \% \mathrm{Eu}^{3+}$ have been grown in the same way as the previous one. Figure 4 shows conductivity as function of temperature for the heterojunction $\mathrm{GaAs} / \mathrm{SnO}_{2}: 2 \% \mathrm{Eu}$ in the dark and under illumination with the same light sources used for excitation of the sample of Figure 3. The overall conductivity is rather low, which is expected, since the external layer is the rare-earth doped $\mathrm{SnO}_{2}$, which presents strong charge compensation and crystallites of nanoscopic dimensions, resulting a very high resistivity. Unlike the heterojunction $\mathrm{SnO}_{2}: 2 \% \mathrm{Eu} / \mathrm{GaAs}$, in this case the illumination with the forth harmonic of the Nd:YAG laser has strong influence in the sample conductivity, since induces electron-hole generation in the $\mathrm{SnO}_{2}$ layer. It is interesting to notice that the $\mathrm{He}-\mathrm{Ne}$ laser has also a permanent effect on the sample, remaining with a higher conductivity on temperature increase when compared to the dark curve, unlike the excitation with the InGaN LED, whose photo-induced conductivity is quite similar to the conductivity variation in the dark.

Current-voltage curves are measured at different temperatures (70 K and $190 \mathrm{~K}$ ) for this sample, in the dark, and after illumination with the same sort of light sources during 6 minutes, prior to data collecting. The results are shown in Figure 5. We have plotted in log scale in order to substantiate the effect of irradiation with the fourth harmonic of the Nd:YAG laser on the conductivity, since this light source increases drastically the sample conductivity, unlike the two other light sources. Besides, independent on the measurement temperature $(70 \mathrm{~K}$ or $190 \mathrm{~K}$ ) it seems a permanent effect. At $70 \mathrm{~K}$ the $\mathrm{He}-\mathrm{Ne}$ laser also yields a

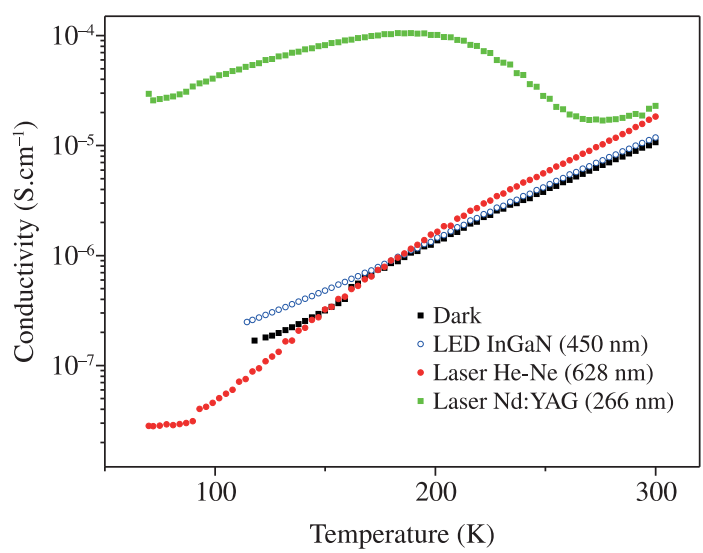

Figure 4. Conductivity as function of temperature for the heterojunction $\mathrm{GaAs} / \mathrm{SnO}_{2}: 2 \% \mathrm{Eu}$ in the dark and under illumination with distinct light sources. 
permanent increase in the conductivity, unlike the InGaN LED, which seems does not affect the carrier generation. At $190 \mathrm{~K}$, both light sources with energy below the $\mathrm{SnO}_{2}$ bandgap, yields negligible effects on the conductivity. This result is in good agreement with the results shown in Figure 3, where the light effects on the GaAs shield are evident only below $100 \mathrm{~K}$. Concerning the effect of the Nd:YAG laser on the sample, it is due to the persistent photoconductivity phenomena ${ }^{32}$. In this case, the capture of photoexcited electrons certainly evolves into a lattice relaxation process, where the electron trapping over a capture barrier is a thermally activated process.

Figure 6 is a simple model of the sample and the light irradiation process, where all the light sources energies are represented. Considering its high transmittance, as seen in Figure 2, the $\mathrm{SnO}_{2}$ layer allows the $450 \mathrm{~nm}$ as well as the $628 \mathrm{~nm}$ monochromatic light reaches the GaAs layer. At 70 $\mathrm{K}$ there is a small conductivity increase due to the He-Ne laser irradiation, but not at $190 \mathrm{~K}$. The InGaN LED (450 nm) does not cause any effect on the current, independent on the temperature. These results can be understood by considering that $628 \mathrm{~nm}$ may cause electron-hole generation as well as

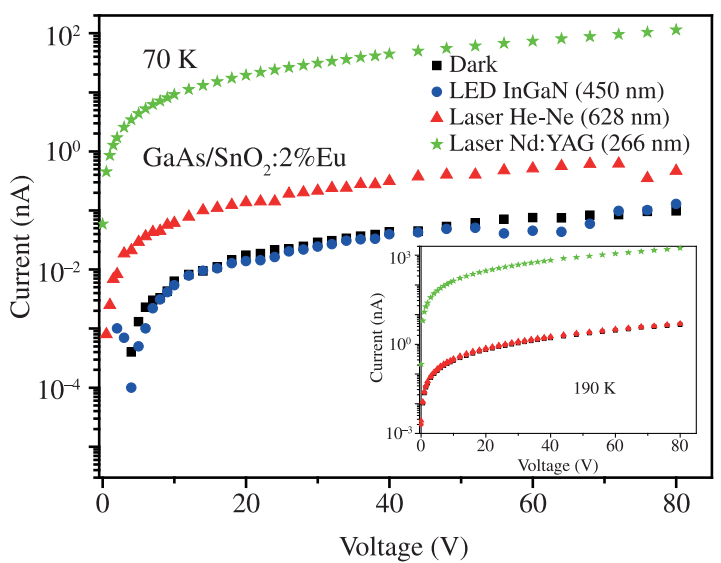

Figure 5. Current - voltage (I-V) curve for the heterojunction GaAs/ $\mathrm{SnO}_{2}: 2 \% \mathrm{Eu}$, in the dark and under illumination with distinct light sources, at $70 \mathrm{~K}$. Inset: I-V curve for the same sample under the same conditions at $190 \mathrm{~K}$. Data are plotted in log scale for better visualization of effects. intrabandgap states excitation in the GaAs layer. At $70 \mathrm{~K}$, the recombination rate is low and the sample remains in the metastable conductive state for a longer time, unlike at $190 \mathrm{~K}$, where the recombination process is faster and there is no measurable photoinduced conductivity variation. An important feature from these data is that the conduction channel is formed by both layers, besides the 2DEG, because the He-Ne source (energy about $1.97 \mathrm{eV}$ ) would not cause any observable effect on the most superficial $\mathrm{SnO}_{2}$ layer. Concerning the illumination with the $450 \mathrm{~nm}$ excitation source, the energy $(2.75 \mathrm{eV})$ is way above the GaAs bandgap $(1.41 \mathrm{eV})$ and may not lead to any allowed transition. On the other hand, the illumination with $266 \mathrm{~nm}$ has energy enough to excite electron-hole generation in the $\mathrm{SnO}_{2}$ layer, being completely absorbed by this oxide semiconductor and then, the conductivity increase is evident.

To obtain some insights on the rare-earth role to the photoinduced transport properties, we have changed the doping to $\mathrm{Ce}^{3+}$. The heterojunction $\mathrm{SnO}_{2}: 1$ at $\% \mathrm{Ce}^{3+} /$ GaAs was deposited also in a similar way to the previous heterojunctions. The current-voltage curve in the dark and after illumination, measured for this sample is as plotted in Figure 7, for $70 \mathrm{~K}$ and $190 \mathrm{~K}$ (inferior inset). The superior inset of Figure 7 is the X-ray diffractogram of this heterojunction, which shows characteristic planes of both heterojunction semiconductors. One shall notice that the current magnitude in this case in much higher than the current magnitude reported in Figure 5, when the $\mathrm{SnO}_{2}$ is the top layer, due to the GaAs layer position. RE-doped $\mathrm{SnO}_{2}$ has strong charge compensation due to the presence of acceptors-like trivalent $\mathrm{RE}^{3+}$ ions, which trap conducting electrons from the naturally n-type $\mathrm{SnO}_{2}$ semiconductor. Concerning the light irradiation, the behavior is rather similar to what is observed for the heterojunction $\mathrm{SnO}_{2}: 2$ at $\% \mathrm{Eu} / \mathrm{GaAs}$, where the GaAs layer acts as a shield for the light irradiation. It is interesting to mention that the effect in this case is slightly different from the results reported in Figure 3, becuse the above $\mathrm{SnO}_{2}$ bandgap light does not cause any effect in the sample conductivity but the above GaAs bandgap light leads to a striking decrease in the sample conductivity. It expected that the $\mathrm{Ce}^{3+}$ doping leads to more ions located at grain boundary because $\mathrm{Ce}^{3+}$ ions are larger

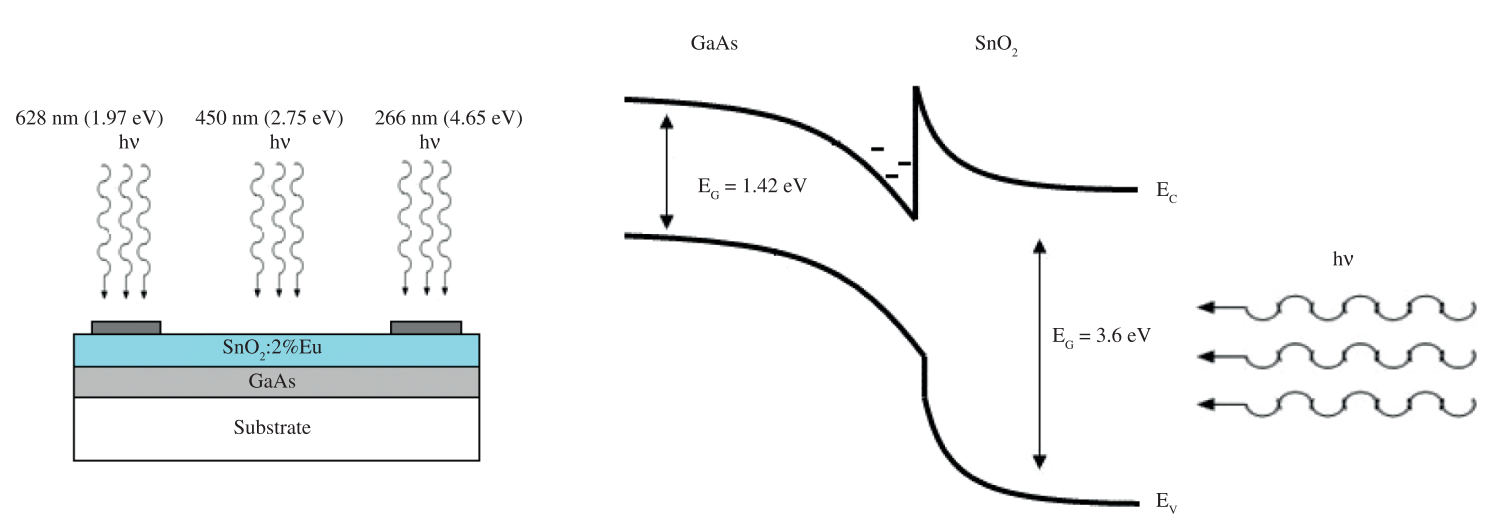

Figure 6. Schematic diagram of the sample structure, and the effects of monochromatic light irradiation on energy band diagram of $\mathrm{GaAs} / \mathrm{SnO}_{2}: 2 \%$ Eu sample. 


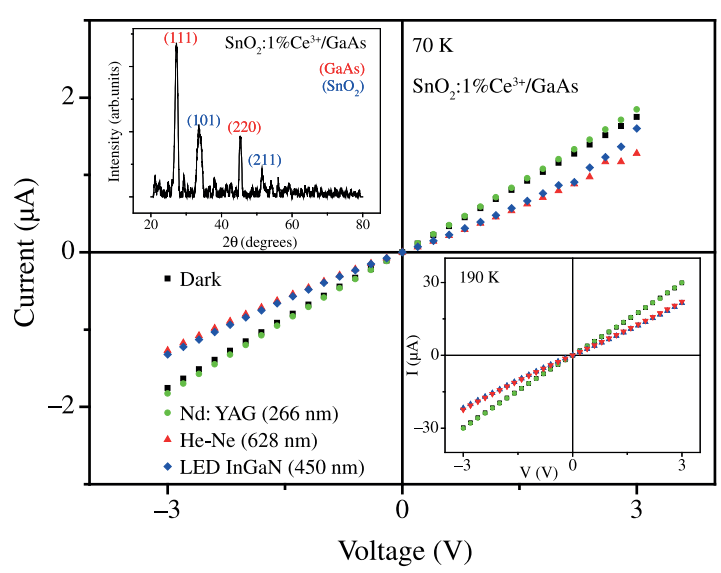

Figure 7. Current - voltage (I-V) curve for the heterojunction $\mathrm{SnO}_{2}: 1 \% \mathrm{Ce} / \mathrm{GaAs}$, in the dark and under illumination with distinct light sources, at $70 \mathrm{~K}$. Inferior inset: I-V curve for the same sample under the same conditions, at $190 \mathrm{~K}$. Superior inset: X-ray diffractogram for this heterojunction.

than $\mathrm{Eu}^{3+}$, and the segregation process is more extreme. Then, it may be suggested that they become localized at layers closer to the 2DEG interface. As the trivalent $\mathrm{Ce}^{3+}$ doping acts as acceptors, they may be trapping the electrons generated by the electron-hole generation in GaAs, which would be excited from the GaAs to the 2DEG, and occupy the higher levels in the potential well. The general effect is decreasing the overall conductivity, since the unpaired holes recombine with the electrons generated by the nonstoichiometry of the compound. More information on the rare-earth doping on the $\mathrm{GaAs} / \mathrm{SnO}_{2}$ heterojunction must come from photoluminescence investigation, which is a matter for a future work.

\section{References}

1. Yadav JB, Patil RB, Puri RK and Vijaya P. Studies on undoped $\mathrm{SnO}_{2}$ thin film deposited by chemical reactive evaporation method. Materials Science and Engineering: B. 2007; 139(1):69-73. http://dx.doi.org/10.1016/j. mseb.2007.01.032

2. Adamowicz B, Izydorkzik W, Izydorkzik J, Klimasek A, Jakubik $\mathrm{W}$ and Zywicki J. Response to oxygen and chemical properties of $\mathrm{SnO}_{2}$ thin-film gas sensors. Vacuum. 2008; 82(10):966-970. http://dx.doi.org/10.1016/j.vacuum.2008.01.003

3. Yang X, Jurkovic MJ, Heroux JB and Wang WI. Molecular beam epitaxial growth of InGaAsN : Sb/GaAs quantum wells for long-wavelength semiconductor lasers. Applied Physics Letters. 1999; 75(2):178-180. http://dx.doi. org/10.1063/1.124311

4. Sze SM. Physics of Semiconductor Devices. New York: John Wiley \& Sons; 1985.

5. Perea-Lopes N, Gonzales-Ortega JA and Hirata GA. Electroluminescence from $\mathrm{Eu}^{3+}$ doped $\mathrm{Sr}_{2} \mathrm{CeO}_{4}$ nanocrystalline thin films. Optical Materials. 2006; 29 (1):43-46. http://dx.doi. org/10.1016/j.optmat.2006.03.006

6. Morais EA, Scalvi LVA, Tabata A, Oliveira JBB and Ribeiro SJL. Photoluminescence of $\mathrm{Eu}^{3+}$ ion in $\mathrm{SnO}_{2}$ obtained by sol-

\section{Conclusions}

The heterojunction electrical conductivity is higher than the conductivity of the individual films with similar thickness. X-ray diffractogram of the heterojunctions $\mathrm{SnO}_{2} / \mathrm{GaAs}$ shows crystallographic planes of GaAs and $\mathrm{SnO}_{2}$. Although the resistive evaporation technique leads to rather inhomogeneous surface and thus, the interface should present a high density of interfacial defects, scanning electron microscopy (SEM) images, previously published, show high interface uniformity, good adherence and fair morphological quality of the interfaces substrate/ $\mathrm{SnO}_{2}$ and $\mathrm{SnO}_{2} / \mathrm{GaAs}$. Then, the enhancement of electrical conductivity of the heterojunction $\mathrm{SnO}_{2}: 2 \% \mathrm{Eu} / \mathrm{GaAs}$ may be due to the formation of small interfacial 2DEG channels.

Monochromatic light excitation on the electrical transport properties shows up the role of the most external layer, which may act as a shield, in the case of top GaAs, or a strong light absorber sink, in the case where the top layer is RE-doped $\mathrm{SnO}_{2}$. Small peculiarities of the excitation on the photoinduced low temperature conductivity suggests the participation of the interfacial channel for the transport properties, explaining the higher conductivity of the heterojunction when compared to the individual deposited layers.

One of the most relevant aspects of $\mathrm{GaAs} / \mathrm{SnO}_{2}$ heterojunctions presented here, is the combination of two simple techniques to deposit semiconductor films, leading to a motivating result concerning the electrical transport. Then, the design of simple devices becomes possible, combining the interface conductivity with the selective emission of rare-earth trivalent ions, located at different sites in the $\mathrm{SnO}_{2}$ matrix.

\section{Acknowledgements}

The authors thank the Brazilian financial sources CNPq and FAPESP for financial support.

gel. Journal of Materials Science. 2008; 43:345-349. http:// dx.doi.org/10.1007/s10853-007-1610-1

7. Brito GES, Ribeiro SJL, Briois V, Dexpert-Ghys J, Santilli $\mathrm{CV}$ and Pulcinelli SH. Short range order evolution in the preparation of $\mathrm{SnO}_{2}$ based materials. Journal of Sol-Gel Science and Technology. 1997; 8(1-3):261-268. http://dx.doi. org/10.1007/BF02436850

8. Dorenbos P. 5d-level energies of $\mathrm{Ce}^{3+}$ and the crystalline environment. III. Oxides containing ionic complexes. Physical Review B. 2001; 64(12):125117-125129. http://dx.doi. org/10.1103/PhysRevB.64.125117

9. Annapurna K, Dwivedi RN, Kundu P and Buddhydu S. Blue emission spectrum of $\mathrm{Ce}^{3+}: \mathrm{ZnO}-\mathrm{B}_{2} \mathrm{O}_{3}-\mathrm{SiO}_{2}$ optical glass. Materials Letters. 2004; 58(5): 787-789. http://dx.doi. org/10.1016/j.matlet.2003.07.012

10. Zhang H, Fu XY, Niu SY, Sun GQ and Xin Q. Luminescence properties of $\mathrm{Li}^{+}$doped nanosized $\mathrm{SnO}_{2}$ : Eu. Journal of Luminescence. 2005; 115(1-2):7-12. http://dx.doi. org/10.1016/j.jlumin.2005.02.008

11. Gu F, Wang SF, Lu MK, Qi YX, Zhou GJ, Xu D, Yuan, DR. Preparation and luminescence characteristics of nanocrystalline $\mathrm{SnO}_{2}$ particles doped with $\mathrm{Dy}^{3+}$. Journal of Crystal Growth. 2003; 255(3-4):357-360. http://dx.doi. org/10.1016/S0022-0248(03)01294-6 
12. Gu F, Wang SF, Lu MK and Qi YX. Luminescent characteristics of $\mathrm{Eu}^{3+}$ in $\mathrm{SnO}_{2}$ nanoparticles. Optical Materials. 2004; 25(1):59-64. http://dx.doi.org/10.1016/ S0925-3467(03)00226-X

13. Morais EA, Scalvi LVA, Ribeiro SJL and Geraldo V. PooleFrenkel effect in Er doped $\mathrm{SnO}_{2}$ thin films deposited by solgel-dip-coating. Physica Status Solidi A. 2005; 202:301-308. http://dx.doi.org/10.1002/pssa.200406919

14. Shannon RD. Revised effective ionic-radii and systematic studies of interatomic distances in halides and chalcogenides. Acta Crystallographica A. 1976; 32(1):751-767. http://dx.doi. org/10.1107/S0567739476001551

15. DuG,CuiY,XiaXC,LiXP,ZhuHC,Zhang BLetal.Visual-infrared electroluminescence emission from $\mathrm{ZnO} / \mathrm{GaAs}$ heterojunctions grown by metal-organic chemical vapor deposition. Applied Physics Letters. 2007; 90(24):243504-243506. http://dx.doi. org/10.1063/1.2748093

16. Tan ST, Zhao JL, Iwan S, Sun XW, Tang X, Ye J et al. $\mathrm{n}-\mathrm{ZnO} / \mathrm{n}-\mathrm{GaAs}$ Heterostructured White Light-Emitting Diode: Nanoscale Interface Analysis and Electroluminescence Studies. IEEE Transactions on Electron Devices. 2010; 57(1):129-233. http://dx.doi.org/10.1109/TED.2009.2034497

17. Cuculescu E, Evtodiev I and Caraman M. Non-equilibrium charge carriers generation - recombination mechanisms at the interface of the $\mathrm{SnO}_{2} / \mathrm{GaSe}$ heterojunction. Thin Solid Films. 2009; 517(7):2515-2518. http://dx.doi.org/10.1016/j. tsf.2008.11.066

18. Maciel Junior JLB, Floriano EA, Scalvi LVA and Ravaro LP. Growth of $\mathrm{Al}_{2} \mathrm{O}_{3}$ thin film by oxidation of resistively evaporated $\mathrm{Al}$ on top of $\mathrm{SnO}_{2}$, and electrical properties of the heterojunction $\mathrm{SnO}_{2} / \mathrm{Al}_{2} \mathrm{O}_{3}$. Journal of Materials Science. 2011; 46:66276632. http://dx.doi.org/10.1007/s10853-011-5613-6

19. Horn K. Electronic Structure of Semiconductor Surfaces. In: Horn K and Scheffler M, editors. Handbook of Surface Science, vol 2. Elsevier; 2000. cap. 7, p. 385-431.

20. Tsui DC. Observation of surface bound state and twodimensional energy band by electron tunneling. Physical Review . 1970; 24: 303-305.

21. Dingle R, Stormer HL, Gossard AC, Wiegman W. Electron mobilities in modulation-doped semiconductor heterojunction superlattices. Applied Physics Letters. 1978; 33:665-667. http:// dx.doi.org/10.1063/1.90457

22. Bark CW, Sharma P, Wang Y, Beak SH, Lee S, Ryu $\mathrm{S}$ et al. Switchable induced polarization in $\mathrm{LaAlO}_{3} / \mathrm{SrTiO}_{3}$ heterostructures. Nano Letters. 2012; 12:1765-1771. PMid:22400486. http://dx.doi.org/10.1021/n13001088

23. Wang Y, Niranjan MK, Jaswal SS and Tsymbal EY. Firstprinciples studies of a two-dimensional electron gas at the interface in ferroelectric oxide heterostructures. Physical Review B. 2009; 80:165130-1-10. http://dx.doi.org/10.1103/ PhysRevB.80.165130

24. Jang HW, Felker DA, Bark CW, Wang Y, Niranjan MK, Nelson $\mathrm{CT}$ et al. Metallic and Insulating Oxide Interfaces Controlled by Electronic Correlations. Science. 2011; 331:886-889. PMid:21330538. http://dx.doi.org/10.1126/science.1198781

25. Wang EY and Legge RN. General Properties of $\mathrm{SnO}_{2}-\mathrm{GaAs}$ and $\mathrm{SnO}_{2}-\mathrm{Ge}$ Heterojunction Photo-Voltaic Cells. IEEE Transactions on Electron Devices. 1978; 25(7):800-803. http:// dx.doi.org/10.1109/T-ED.1978.19173

26. Pinheiro MAL, Pineiz TF, Morais EA, Scalvi LVA, Saeki MJ and Cavalheiro AA. Schottky emission in nanoscopically crystallized Ce-doped $\mathrm{SnO}_{2}$ thin films deposited by sol-gel-dipcoating. Thin Solid Films. 2008; 517:976-981. http://dx.doi. org/10.1016/j.tsf.2008.07.001

27. Pineiz TF, Scalvi LVA, Saeki MJ and Morais EA. Interface Formation and Electrical Transport in $\mathrm{SnO}_{2}: \mathrm{Eu}^{3+} / \mathrm{GaAs}$ Heterojunction deposited by Sol-Gel Dip-Coating and Resistive Evaporation. Journal of Electronic Materials. 2010;39:1170-1176. http://dx.doi.org/10.1007/s11664-010-1161-0

28. Castro MC, Morais EA, Scalvi LVA and Ruggiero LO. Utilização de Cloreto de Érbio como Precursor na Dopagem de GaAs pelo Método de Evaporação Resistiva. Matéria. 2004; 9:392-398.

29. Powder Diffraction File, Inorganic. vol. 21. Swarthmore: JCPDS; 1983.

30. Morais EA, Scalvi LVA, Cavalheiro AA, Tabata A and Oliveira JBB. Rare earth centers properties and electron trapping in $\mathrm{SnO}_{2}$ thin films produced by sol-gel route. Journal of Non-Crystalline Solids. 2008; 354:4840-4845. http://dx.doi. org/10.1016/j.jnoncrysol.2008.04.029

31. Morais EA and Scalvi LVA. Electron trapping of laserinduced carriers in Er-doped $\mathrm{SnO}_{2}$ thin films. Journal of the European Ceramic Society. 2007; 27: 3803-3806. http://dx.doi. org/10.1016/j.jeurceramsoc.2007.02.037

32. Morais EA, Scalvi LVA, Geraldo V, Scalvi RMF, Ribeiro SJL, Santilli CV et al. Electro-optical properties of Erdoped $\mathrm{SnO}_{2}$ thin films. Journal of the European Ceramic Society. 2004; 24:1857-1860. http://dx.doi.org/10.1016/ S0955-2219(03)00515-6 